Campos Neutrais - Revista Latino-Americana de Relações Internacionais

Vol. 1 No 1, Janeiro - Abril de 2019

\title{
Cultura Política e democracia no Brasil dos anos $60^{1}$
}

\author{
Rodrigo Stumpf González*
}

Resumo: No período recente o Brasil tem vivido momentos de grande instabilidade política, com o afastamento de uma presidenta e a eleição de um ex-militar conhecido por elogiar o período ditatorial. Mas este tipo de evento não é uma novidade na história política do país. A década de 1960 também foi turbulenta no sistema político brasileiro. Até que ponto existia uma cultura política que sustentasse a democracia naquele período? Teria esta cultura se modificado ao longo do tempo, favorecendo o golpe? Tomando da concepção de Almond e Verba (1989) a noção de congruência, este trabalho busca analisar o período democrático brasileiro entre as eleições de 1960 e o golpe militar de 1964, tentando verificar até que ponto se desenvolvia na sociedade brasileira uma cultura política democrática, capaz de dar suporte à manutenção do regime.

Palavras-chave: cultura política, democracia, ditadura, militares, Brasil

Abstract: In the recent period Brazil has experienced moments of great political instability, with the removal of a president and the election of an ex-military known for praising the dictatorial period. But this type of event is not new in the country's political history. The 1960s were also turbulent in the Brazilian political system. To what extent was there a political culture that supported democracy in that period? Would this culture have changed over time, favoring the coup? From the conception of Almond and Verba (1989), the notion of congruence, this work seeks to analyze the Brazilian democratic period between the 1960 elections and the 1964 military coup, trying to verify to what extent a democratic political culture developed in Brazilian society, able to support the maintenance of the regime.

Keywords: political culture, democracy, dictatorship, military, Brazil

Este trabalho contou com o apoio do CNPQ por meio de bolsa de produtividade em Pesquisa Professor do Programa de Pós-Graduação em Ciência Política da UFRGS. 
Campos Neutrais - Revista Latino-Americana de Relações Internacionais

Vol. 1 No 1, Janeiro - Abril de 2019

\section{Introdução}

No período recente o Brasil tem vivido momentos de instabilidade política, com o afastamento de uma presidente com argumentos de legalidade duvidosa, mas sustentados ela maioria do Congresso Nacional e por uma parcela razoável da população. Posteriormente foi eleito presidente da república um ex-militar conhecido por elogiar o período ditatorial. Mas este tipo de evento não é uma novidade na história política do país. A década de 1960 também foi turbulenta no sistema político brasileiro. Em geral o período é recordado por seus momentos autoritários, mais que pelos democráticos.

Seu período democrático foi curto, durando até o1 de abril de 1964. Os anos que se seguiram foram caracterizados por um paulatino recrudescimento do autoritarismo.

No entanto, apesar das atribulações, alguns aspectos positivos podem ser identificados. A democracia foi mais resistente do que poderia de se esperar. Ela resistiu a diferentes ataques, que começaram em meados dos anos 50, vindo a perecer apenas uma década após.

Até que ponto existia uma cultura política que sustentasse a democracia naquele período? Teria esta cultura se modificado ao longo do tempo, favorecendo o golpe?

Estas são questões difíceis de serem respondidas retrospectivamente. Este trabalho buscará algumas respostas, pela análise das manifestações de alguns atores políticos do período, fundando-se na perspectiva proposta por Cruz (2005), para quem é possível resgatar aspectos da cultura política de um período pela análise das posições de agentes envolvidos no contexto.

Tomando da concepção de Almond e Verba (1989) a noção de congruência, este trabalho busca analisar o período democrático brasileiro entre as eleições de 1960 e o golpe militar de 1964, tentando verificar até que ponto se desenvolvia na sociedade brasileira uma cultura política democrática, capaz de dar suporte à manutenção do regime.

Na primeira parte do texto são apresentados o conceito de cultura política e sua utilização neste trabalho. Em seguida, discutido o contexto político brasileiro a partir do final dos anos 50 até a consolidação do regime autoritário. 
Campos Neutrais - Revista Latino-Americana de Relações Internacionais Vol. 1 No 1, Janeiro - Abril de 2019

Em seguida são analisadas manifestações de diversos atores políticos envolvidos com os principais eventos relacionados às mudanças do regime político brasileiro: a renúncia de Jânio Quadros e posse de João Goulart, a emenda parlamentarista e sua derrogação por plebiscito, o golpe militar e a decretação do AI5. Ao final são apresentadas algumas conclusões preliminares oriundas do material avaliado.

\section{Cultura Política e democracia}

No início dos anos 60 foi desenvolvido o modelo de análise proposto por Almond e Verba (1989) para a estabilidade dos regimes políticos, baseado no conceito de cultura política.

Para os autores um padrão de distribuição de orientações cognitivas, afetivas e avaliativas para com objetos políticos, por parte de uma população se constitui em sua cultura política. Determinados padrões, que eles conceituam de cultura cívica,seriam os mais apropriados para a manutenção da democracia.

A proposição dos autores remete ao modelo de análise sistêmica de Easton (1957), que identifica como um dos elementos que mantém o equilíbrio dos sistemas políticos sendo a relação entre (inputs) sob a forma demandas e apoios e outputs, como decisões de políticas governamentais.

$\mathrm{O}$ apoio aos regimes políticos segundo Easton pode ser diferenciado entre apoio difuso e apoio específico. Enquanto o apoio específico depende de resultados das políticas governamentais, o apoio difuso seria fundado na congruência entre os valores e atitudes pessoais dos cidadãos e os valores subjacentes ao sistema político existente.

Para Almond e Verba (1989), na medida em que os padrões de apoio sejam congruentes com o tipo de regime político existente, este seria mais estável. A estabilidade da democracia estaria, assim, relacionada à existência a padrões consistentes de apoio a este regime, desenvolvido a partir da existência de uma cultura política favorável à democracia.

No entanto, metodologicamente, há uma dificuldade de aplicação do modelo de análise de cultura política de Almond e Verba (1989) para um período passado do qual não há dados coletados sob a forma de surveys com uma amostra da população brasileira, na década de 1960 . 
Campos Neutrais - Revista Latino-Americana de Relações Internacionais Vol. 1 No 1, Janeiro - Abril de 2019

Uma alternativa para uma análise da cultura política de períodos no passado é proposta por Cruz (2005). A autora utilizada como indicador dos valores dominantes de uma sociedade em determinado momento os discursos e idéias defendidas por lideranças políticas proeminentes nesta sociedade.

Admitindo que as manifestações públicas de atores políticos são utilizadas como forma de busca de apoio e legitimação das lideranças, a autora conclui que estas tendem a dizer o que a população quer ouvir, adaptando estrategicamente seus discursos ao que é socialmente apoiado ou tolerado.

As lideranças serviriam como árbitros da construção dos limites possíveis e aceitáveis para a política para uma determinada sociedade.

Assim, tomando por base as manifestações destes atores políticos no período analisado, seria possível inferir que tipo de idéias e valores tinham eco na sociedade e no sistema político naquele momento.

Utilizando-se o modelo teórico de Cruz (2005), este estudo será feito a partir da identificação das posições de alguns dos atores centrais do processo político brasileiro na década de 1960 e seus apelos à sociedade.

São analisadas aqui manifestações atores envolvidos no processo ruptura da democracia brasileira na década de 1960, em alguns dos momentos chave. Inicia-se com a carta de renúncia de Jânio Quadros, o discurso de Leonel Brizola pela legalidade, na defesa da posse de João Goulart, a manifestação dos ministros militares contra a posse de Jango, os discursos de posse de Jango e Tancredo Neves após a aprovação do parlamentarismo, todos de 1961. Passa-se ao discurso de Jango na Central do Brasil e ao preâmbulo do Ato Institucional $\mathrm{n}^{\circ} 1$ editado pelos militares após o golpe, de 1964 e fecha-se com o preâmbulo do Ato Institucional n ${ }^{\circ} 5$, de 1968.

Embora esta seja uma pequena amostra, é indicativa de algumas das posições dominantes na política brasileira da época, que buscavam mobilizar o apoio da população brasileira.

\section{Os anos 60 no Brasil e seus antecedentes políticos}

Provavelmente as origens das turbulências políticas sofridas pelo Brasil na década de 60 têm vários antecedentes no passado, em especial na década anterior. 
Campos Neutrais - Revista Latino-Americana de Relações Internacionais Vol. 1 No 1, Janeiro - Abril de 2019

Em agosto de 1954, na eminência de um golpe de Estado, o Presidente Getúlio Vargas se suicidou, provocando revoltas populares que inviabilizaram o sucesso dos golpistas.

A eleição seguinte, de Juscelino Kubitschek também foi marcada por ameaças de revolta militar e tentativas de impedir a posse do novo presidente. Embora o relativo sucesso de seu "Plano de Metas" na modernização da economia brasileira, o período também foi marcado por acusações de corrupção da oposição. (Lafer, 2002)

O governo de Kubitschek teve certo sucesso na modernização do país, com a atração das primeiras montadoras de automóveis e a ampliação das estradas pavimentadas. Seu governo foi coroado com a inauguração de Brasília, nova capital do país.

A nova década começou com um novo presidente. Em 3 de outubro de 1960 foi eleito Jânio Quadros, por uma aliança conservadora que incluía a UDN. No entanto, pelo sistema eleitoral brasileiro da época, a votação para Presidente e Vice-Presidente era feita separadamente, o que levou à eleição como Vice de Jânio Quadros a João Goulart, o Jango, do PTB que havia sido ministro do trabalho de Getúlio Vargas e Vice-Presidente de Juscelino Kubitschek. Ambos tomam posse em 31 de janeiro de 1961.

O governo de Jânio Quadros durou pouco, tendo o presidente renunciado ao cargo em 25 de agosto de 1961, em circunstâncias que nunca ficaram totalmente esclarecidas.

Neste breve período tomou algumas decisões polêmicas: proibição do bikini nas praias e a condecoração de Che Guevara com a Ordem do Cruzeiro do Sul.

A renúncia de Jânio provocou pânico nos setores mais conservadores, diante da perspectiva de posse de João Goulart, visto como um radical de esquerda.

As credenciais de radical de Jango eram duvidosas. Oriundo de uma família de latifundiários, seus atos mais radicais, identificados com o trabalhismo de Getúlio Vargas se limitavam à defesa da modernização do país e o reconhecimento de direitos dos trabalhadores já amplamente reconhecidos em economias capitalistas desenvolvidas.

Para complicar a situação, Goulart encontrava-se em viagem à China. O vazio de poder aparentemente facilitava os posicionamentos golpistas. Porém o golpe mais uma vez não teve sucesso. Neste caso graças a uma ampla mobilização social, iniciada 
Campos Neutrais - Revista Latino-Americana de Relações Internacionais

Vol. 1 No 1, Janeiro - Abril de 2019

pelo Governador do Estado do Rio Grande do Sul, Leonel Brizola, que também era cunhado de Jango.

Durante pouco mais de uma semana Brizola fico entrincheirado no Palácio Piratini, aguardando um ataque militar e comandado uma cadeia nacional de rádio, mobilizando a população contra o golpe, forçando os adversários de João Goulart a negociar uma alternativa.

O acordo para a aceitação da posse de Jango incluiu uma modificação da Constituição de 1946, transformando o Brasil em um sistema parlamentarista. Embora o país tenha mantido o parlamentarismo durante o período imperial, desde a proclamação da república em 1889 o presidencialismo tinha sido o sistema adotado. O parlamentarismo durou somente de 1961 a 1963. Um plebiscito foi convocado, tendo sido aprovado o retorno ao presidencialismo.

Com a devolução dos poderes, a pauta do presidente João Goulart se centrou nas chamadas "reformas de base", que deveriam gerar uma melhor distribuição de renda e ampliar a modernização da economia, envolvendo temas como a reforma agrária, a reforma administrativa e o controle de envio de lucros ao exterior por empresas estrangeiras.

A popularidade de Jango e de outras lideranças trabalhistas, como Leonel Brizola tornava possível uma vitória nas eleições previstas para 1965, reforçando a aliança no governo, para temor da oposição conservadora.

A conjuntura política brasileira também foi influenciada pelo contexto político internacional. A guerra fria, conflito entre os EUA e a URSS pela hegemonia política global iniciada após a II Guerra Mundial também afetou a política estadunidense para o continente americano. Nos anos 50, o Macartismo é um exemplo de como foi provocada uma histeria anticomunista na sociedade e no governo dos EUA, que afetou também sua política externa.

Em uma combinação entre a doutrina Monroe e a Doutrina Truman, os EUA viam a América Latina como sua área de influência e reserva de segurança. A aplicação destes princípios no combate à ameaça de influência soviética no continente foi denominada de 'Doutrina de Segurança Nacional”, equiparando os movimentos políticos internos de esquerda a agentes do "comunismo internacional", como elementos subversivos (Comblin, 1980; Alves, 2005). 
Campos Neutrais - Revista Latino-Americana de Relações Internacionais Vol. 1 No 1, Janeiro - Abril de 2019

A vitória da revolução Cubana, inicialmente reconhecida pelo Governo de Eisenhower como tendo elementos positivos, foi logo condenada por suas medidas contra interesses do capital estadunidense na ilha e aproximação da URSS.

O Governo Kennedy herdou os planos da fracassada invasão da Baía dos Porcos por mercenários anti-castristas financiados pela CIA. A crise dos mísseis de 1962 chegou próximo da deflagração de uma guerra entre as duas superpotências.

Neste contexto, o governo dos Estados Unidos tinha pouca tolerância por qualquer governo reformista visto como potencialmente desestabilizador e aliado dos comunistas. Não foi diferente com o Governo de João Goulart, tendo os Governos de Kennedy e Lyndon Johnson apoiado financeiramente a oposição ao governo brasileiro e disponibilizado apoio inclusive militar para o Golpe de 1964, para o caso de haver resistência. (Alves, 2005)

A desconfiança com o Governo Brasileiro foi ampliada pelo desenvolvimento de uma política externa que rompeu com o alinhamento com as posições do Governo dos EUA (Vizentini, 1995).

Assim, entre fatores internos e pressões externas, a democracia brasileira acaba por perecer em 1964. Seria esta a crônica de uma morte anunciada ou havia possibilidade de alternativas, que possa ser vislumbrada no posicionamento das lideranças políticas envolvidas no processo.

Esta é a questão que passa a ser analisada com base nas manifestações de alguns dos atores políticos brasileiros no período.

\section{A trajetória do regime político brasileiro nos anos 60 e seus atores}

Embora alguns momentos anteriores de instabilidade nos anos 50 já referidos, a eleição de Jânio Quadro era a quarta eleição presidencial em seqüência, o que poderia indicar um mínimo de estabilidade do regime.

Esta estabilidade começa a ser quebrada com a renúncia do presidente. Em curta carta de renuncia os motivos são pouco desenvolvidos, com a muito comentada referência a forças terríveis levantadas contra o presidente:

Desejei um Brasil para os brasileiros, afrontando, nesse sonho, a corrupção, a mentira e a covardia que subordinam os interesses gerais aos apetites e às ambições de grupos ou de indivíduos, inclusive do exterior. Sinto-me, porém, esmagado. Forças terríveis levantam-se contra mim e me intrigam ou infamam, até com a desculpa de colaboração. 
Se permanecesse, não manteria a confiança e a tranquilidade, ora quebradas, indispensáveis ao exercício da minha autoridade. Creio mesmo que não manteria a própria paz pública. (Quadros, 1961)

A carta não faz nenhuma referência à democracia, mas dá a entender que a motivação está relacionada à falta de poder para aplicar suas decisões e manter a paz pública. O apelo central da carta é pela manutenção da ordem, mais do que da democracia.

A renúncia de Jânio leva a uma manifestação de veto dos ministros militares à perspectiva da posse de Jango. Apelam ao Congresso Nacional como instância que poderia evitar a posse. O golpismo é escondido sob o manto de cumprimento do dever d manter a ordem.

No cumprimento de seu dever constitucional de responsáveis pela manutenção da ordem, da lei e das próprias instituições democráticas, as Forças Armadas do Brasil, através da palavra autorizada dos seus ministros, manifestam a Sua Excelência, o Sr. Presidente da República, como já foi amplamente divulgado, a absoluta inconveniência, na atual situação, do regresso ao País do Vice-Presidente, Sr. João Goulart. (Denys, Heck e Moss, 1961)

O argumento central contra posse seria a posição ideológica de Jango e a ameaça do comunismo internacional, reforçada pela recente visita do então vicepresidente à URSS e China.

Ora, no quadro de grave tensão internacional, em que vive dramaticamente o mundo dos nossos dias, com a comprovada intervenção do comunismo internacional na vida das nações democráticas e, sobretudo, nas mais fracas, avultam, à luz meridiana, os tremendos perigos a que se acha exposto o Brasil. (Denys, Heck e Moss, 1961)

A resposta ao veto dos militares veio em pronunciamento do Governador do Estado do Rio Grande do Sul, Leonel Brizola, em cadeia de rádio, em defesa do cumprimento da Constituição, em resistência inclusive armada à qualquer tentativa de golpe ou invasão militar.

O tom foi dramático, de apelo e denúncia. Conclamava à resistência, chamando a si o exemplo de quem promete perecer lutando se necessário:

Não pretendemos nos submeter. Que nos esmaguem! Que nos destruam! Que nos chacinem, neste Palácio! Chacinado estará o Brasil com a imposição de uma ditadura contra a vontade de seu povo. Esta rádio será silenciada tanto aqui como nos transmissores. O certo porém é que não será silenciada sem balas. Tanto aqui como nos transmissores estamos guardados por fortes contingentes da Brigada Militar. (Brizola, 1961) 
Campos Neutrais - Revista Latino-Americana de Relações Internacionais

Vol. 1 No 1, Janeiro - Abril de 2019

Por outro lado, o governador ataca diretamente o argumento dos militares, negando qualquer alinhamento nem com os Estados Unidos nem com a União Soviética, com um manifesto por um Brasil independente.

Muita atenção, meus conterrâneos, para esta comunicação. Ontem à noite o Sr. Ministro da Guerra, Marechal Odílio Denys, soldado no fim de sua carreira, com mais de 70 anos de idade, e que está adotando decisões das mais graves, as mais desatinadas, declarou através do 'Repórter Esso' que não concorda com a posse do Sr. João Goulart, que não concorda que o Presidente constitucional do Brasil exerça suas funções legais! Porque, diz ele numa argumentação pueril e inaceitável, isso significa uma opção entre comunismo ou não. Isso é pueril, meus conterrâneos. Isso é pueril, meus patrícios! Não nos encontramos nesse dilema. Que vão essas ou aquelas doutrinas para onde quiserem. Não nos encontramos entre uma submissão à União Soviética ou aos Estados Unidos. Tenho uma posição inequívoca sobre isto. Mas tenho aquilo que falta a muitos anticomunistas exaltados deste país, que é a coragem de dizer que os Estados Unidos da América, protegendo seus monopólios e trustes, vão espoliando e explorando esta Nação sofrida e miserabilizada. Penso com independência. Não penso ao lado dos russos ou dos americanos. Penso pelo Brasil e pela República. Queremos um Brasil forte e independente. Não um Brasil escravo dos militaristas e dos trustes e monopólios norteamericanos. Nada temos com os russos. Mas nada temos também com os americanos, que espoliam e mantêm nossa pátria na pobreza, no analfabetismo e na miséria. (Brizola, 1961)

Diferentemente do que acabou ocorrendo pouco mais de uma década depois com o Palácio de La Moneda, no Chile, o Palácio Piratini acabou não sendo bombardeado. A conciliação foi feita pela aprovação da emenda constitucional n. 4, em 2 de setembro de 1961, passando o sistema de governo de presidencialista para parlamentarista e esvaziando-se os poderes do Presidente.

A posição conciliadora pode ser identificada no discurso de posse de Tancredo Neves como Primeiro Ministro em 8 de setembro de 1961. Embora Neves tivesse um passado de identificação com o trabalhismo, tendo sido ministro de Getúlio Vargas, vinha de setores muito mais moderados.

O discurso apela pela conciliação, avalizando uma suposta solidez e maturidade da democracia brasileira, capaz de encontrar na lei a solução para suas crises:

A 25 de agosto, um Presidente da República, eleito por esmagadora maioria, renunciava ao seu mandato, imprevista e abruptamente, deixando 70 milhões de brasileiros mergulhados na mais profunda perplexidade. Não seria muito difícil prever 
as consequências de gesto semelhante em qualquer país do mundo que estivesse atravessando condições idênticas às do Brasil. Nenhum dom profético especial se exigiria de qualquer analista para vaticinar a superveniência do caos, da guerra civil, de uma ditadura, de um retrocesso, enfim, na evolução democrática da República. É possível que ainda não se tenha dado à nossa vocação jurídica toda a transcendental importância que merece. No entanto, bastaria um olhar retrospectivo à nossa história para perceber, de modo límpido, que $\mathrm{o}$ instrumento revolucionário que por excelência manejamos tem sido, e continua sendo, nos dias que correm, a lei. (Neves, 2010; 147)

A tentativa de redução das tensões políticas faz com que chegue a negar os próprios fatos que ocorreram nas duas semanas anteriores, elogiando o papel do Congresso Nacional e das Forças Armadas na preservação da democracia, justamente dois dos órgãos diretamente ligados à conspiração pelo golpe que vinha ocorrendo:

Eis por que o episódio da renúncia, apesar do seu caráter abrupto e chocante, a ninguém encontrou desprevenido. $\mathrm{O}$ povo, os seus mandatários nas duas Casas do Congresso Nacional, as forças do capital e do trabalho, os intelectuais e, sobretudo, as Forças Armadas brasileiras, não tiveram outro pensamento senão o de preservar as instituições democráticas e o de assegurar a posse do Presidente João Goulart. (Neves, 2010; 148)

O Presidente João Goulart havia tomado posse um dia antes, em 7 de setembro. O discurso, embora ao final faça um agradecimento às diversas forças políticas - Congresso, militares, Igreja Católica, pela manutenção da Constituição, faz questão de chamar a atenção para a origem no voto popular de sua legitimidade, bem como a interferência da população para a garantia de sua posse.

Assumo a Presidência da República consciente dos graves deveres que me incumbem perante a Nação. A minha investidura, embora sob a égide de um novo sistema, consagra respeitoso acatamento à ordem constitucional. Subo ao poder ungido pela vontade popular, que me elegeu duas vezes VicePresidente da República e que, agora, em impressionante manifestação de respeito pela legalidade e pela defesa das liberdades públicas, uniu--se, através de todas as suas forças, para impedir que a decisão soberana fosse desrespeitada. (Goulart, 1961)

Já na posse, no entanto, o novo Presidente mostra sua desconformidade com o mecanismo encontrado para permitir a sua investidura. O apelo direto ao povo aparece na defesa do referendo popular às decisões políticas, que é o anúncio precoce do plebiscito sobre o sistema de governo que ocorreu em janeiro de 1963, que aprovou o retorno ao Presidencialismo. 
Permitam, entretanto, Senhores Congressistas, neste momento, uma reflexão que suponho seguramente tão sua quanto minha. Souberam Vossas Excelências resguardar, com firmeza, com honra e com sabedoria, o exercício e a defesa do mandato que a Nação lhes confiou. Cumpre-nos, agora, mandatários do povo, fiéis ao preceito básico de que todo poder dele mesmo emana, devolver apalavra e a decisão à vontade popular, que nos manda e que nos julga, para que ela própria dê o seu referendum supremo às decisões políticas que em seu nome estamos solenemente assumindo neste instante. (Goulart, 1961)

Com poderes restituídos, o Presidente João Goulart fez da proposta de uma mudança do modelo econômico brasileiro o centro de seu programa de governo, o que foi denominado de Reformas de Base.

Um dos eventos marcantes da defesa destas propostas, que de certa forma já poderia se considerar uma antecipação da campanha eleitoral de 1965 foi o comício realizado na Estação Central do Brasil, no Rio de Janeiro, em 13 de março de 1964.

Em seu discurso, Jango contrapõe concepções de democracia, defendendo uma democracia popular, vinculada às reformas, em contraponto a uma democracia das elites:

Chegou-se a proclamar, até, que esta concentração seria um ato atentatório ao regime democrático, como se no Brasil a reação ainda fosse a dona da democracia, e a proprietária das praças e das ruas. Desgraçada a democracia se tiver que ser defendida por tais democratas.

Democracia para esses democratas não é o regime da liberdade de reunião para o povo: o que eles querem é uma democracia de povo emudecido, amordaçado nos seus anseios e sufocado nas suas reinvindicações.

A democracia que eles desejam impingir-nos é a democracia antipovo, do anti-sindicato, da anti-reforma, ou seja, aquela que melhor atende aos interesses dos grupos a que eles servem ou representam.

A democracia que eles querem é a democracia para liquidar com a Petrobrás; é a democracia dos monopólios privados, nacionais e internacionais, é a democracia que luta contra os governos populares e que levou Getúlio Vargas ao supremo sacrifício. (Goulart, 1964)

A democracia aparece como um conceito em disputa: a democracia como manutenção da ordem contra a democracia como instrumento de mudança. $\mathrm{O}$ contraponto entre uma concepção minimalista e elitista da democracia e uma concepção maximalista, em que a democracia tem um fim, que é a redução das desigualdades.

Hoje, com o alto testemunho da Nação e com a solidariedade do povo, reunido na praça que só ao povo pertence, o governo, que 
é também o povo e que também só ao povo pertence, reafirma os seus propósitos inabaláveis de lutar com todas as suas forças pela reforma da sociedade brasileira. Não apenas pela reforma agrária, mas pela reforma tributária, pela reforma eleitoral ampla, pelo voto do analfabeto, pela elegibilidade de todos os brasileiros, pela pureza da vida democrática, pela emancipação econômica, pela justiça social e pelo progresso do Brasil. (Goulart, 1964)

Assim, apesar dos diversos eventos de magnitude ocorridos entre 1960 e 1964, a democracia sobreviveu. No discurso dos atores aparecem em comum a defesa da ordem legal. Para uns, no entanto, esta ordem é representada pela Constituição e pela vontade popular. Para outros, na defesa de valores tradicionais, identificando-se com o anti-comunismo da guerra fria.

Para os primeiros, como João Goulart, a ordem constitucional pode ser alterada para a defesa dos interesses populares e na busca da justiça social. Para os segundos, ela pode ser subvertida na defesa de valores superiores, como a família e a propriedade.

É esta segunda concepção que triunfa, com o golpe de 01 de abril e 1964. Os militares, com apoio de setores civis conservadores, derrubam o presidente.

Eles reconhecem a ruptura da ordem, mas constroem um discurso de legitimidade que estranhamente é fundamentado no conceito de revolução, de cuja conspiração eram acusados os que foram afastados.

Esta posição é apresentada no Ato Institucional $\mathrm{N}^{\circ}{ }^{1}$, de 9 de abril de 1964, um misto de manifesto e documento legal. Seu preâmbulo aparece como um Manifesto à Nação, justificando a legitimidade do golpe. O seu corpo regula a situação jurídica, dando uma base de legalidade ao novo regime.

\section{À NAÇÃO}

É indispensável fixar o conceito do movimento civil e militar que acaba de abrir ao Brasil uma nova perspectiva sobre o seu futuro. O que houve e continuará a haver neste momento, não só no espírito e no comportamento das classes armadas, como na opinião pública nacional, é uma autêntica revolução.

A revolução se distingue de outros movimentos armados pelo fato de que nela se traduz, não o interesse e a vontade de um grupo, mas o interesse e a vontade da Nação.

A revolução vitoriosa se investe no exercício do Poder Constituinte. Este se manifesta pela eleição popular ou pela revolução. Esta é a forma mais expressiva e mais radical do Poder Constituinte. Assim, a revolução vitoriosa, como Poder 
Constituinte, se legitima por si mesma. Ela destitui o governo anterior e tem a capacidade de constituir o novo governo. Nela se contém a força normativa, inerente ao Poder Constituinte. Ela edita normas jurídicas sem que nisto seja limitada pela normatividade anterior à sua vitória. Os Chefes da revolução vitoriosa, graças à ação das Forças Armadas e ao apoio inequívoco da Nação, representam o Povo e em seu nome exercem o Poder Constituinte, de que o Povo é o único titular.

O preâmbulo caracteriza o movimento golpista de revolução e identifica as Forças Armadas como sua força motriz. Os conceitos centrais, além de revolução são os de Poder Constituinte, de Nação e de Povo. O primeiro como instrumento concreto que funda a nova ordem, os outros dois abstratos, que legitimam as forças armadas como sua representante, mas sem necessidade de consulta.

O presente Ato institucional só poderia ser editado pela revolução vitoriosa, representada pelos Comandos em Chefe das três Armas que respondem, no momento, pela realização dos objetivos revolucionários, cuja frustração estão decididas a impedir. Os processos constitucionais não funcionaram para destituir o governo, que deliberadamente se dispunha a bolchevizar o País.

Fica, assim, bem claro que a revolução não procura legitimar-se através do Congresso. Este é que recebe deste Ato Institucional, resultante do exercício do Poder Constituinte, inerente a todas as revoluções, a sua legitimação.(BRASIL, 1964)

Não há neste documento qualquer apelo á democracia ou necessidade de legitimação por meios instrumentais. É o reconhecimento da virtù maquiaveliana como criadora da nova ordem. Deixa claro que sua legitimidade não advém do Congresso Nacional, rejeitando uma subordinação às forças políticas legitimadas pela antiga ordem. A motivação é a incapacidade da antiga ordem de combater o inimigo comunista

Além dos condottieri, este apelo traz à memória o Sebastianismo da história portuguesa, com a necessidade de líderes fortes, e a experiência fascista, do apelo direto entre líderes e massa. Não por acaso se atribui a Francisco Campos, jurista que redigiu a Constituição do Estado Novo, de 1937, ter colaborado na construção do ato.

Passados alguns anos, um outro ato institucional, o de número 5, mudou o discurso de legitimação:

O PRESIDENTE DA REPÚBLICA FEDERATIVA DO BRASIL, ouvido o Conselho de Segurança Nacional, e

CONSIDERANDO que a Revolução Brasileira de 31 de março de 1964 teve, conforme decorre dos Atos com os quais se institucionalizou, fundamentos e propósitos que visavam a dar 
ao País um regime que, atendendo às exigências de um sistema jurídico e político, assegurasse autêntica ordem democrática, baseada na liberdade, no respeito à dignidade da pessoa humana, no combate à subversão e às ideologias contrárias às tradições de nosso povo, na luta contra a corrupção, buscando, deste modo, "os. meios indispensáveis à obra de reconstrução econômica, financeira, política e moral do Brasil, de maneira a poder enfrentar, de modo direito e imediato, os graves e urgentes problemas de que depende a restauração da ordem interna e do prestígio internacional da nossa pátria" (Preâmbulo do Ato Institucional $\mathrm{n}^{0}$ 1, de 9 de abril de 1964); (BRASIL, 1968)

Pode parecer talvez uma ironia que o ato que mudanças mais radicais tenha provocado na ordem jurídica, colocando os Presidentes militares acima da ordem constitucional e abrindo caminho para o período de maior repressão política da história brasileira, seja justificado pela proteção da ordem democrática e no respeito à dignidade humana. A mudança pode ser atribuída à intervenção de novos autores, mais cínicos e menos dispostos a dizer abertamente que seu poder advém da força e suas motivações do anti-comunismo.

\section{As palavras, a democracia e o golpe}

Teria sido inevitável o golpe militar de 1964? A explicação de Santos (1986) para o golpe é de natureza institucional. A divisão de forças levara a uma paralisia decisória, que não possuía solução dentro das regras constitucionais, gerando um impasse que levou ao apelo à intervenção dos militares por parte da oposição conservadora. A divisão entre os militares e o interesse em manter-se no poder afastou o modelo de "golpe cirúrgico", cancelando eleições e mantendo-se no poder por 21 anos.

No entanto, é possível verificar que a questão institucional não é suficiente para explicar o golpe. Outros países já sofreram situações de paralisia semelhante, com impasses na relação executivo-legislativo como os EUA no Governo Obama e a Argentina, em momentos do Governo de Cristina Kirschner.

Assim, uma conjuntura favorável à proposta golpista, com acirramento das posições políticas e uma população que havia incorporado no seu cotidiano a defesa de soluções não institucionais como naturalizadas deve ser levado em conta.

Do ponto de vista das forças políticas envolvidas no processo, pode se identificar um discurso centrado na defesa das instituições e da democracia no início 
Campos Neutrais - Revista Latino-Americana de Relações Internacionais

Vol. 1 No 1, Janeiro - Abril de 2019

dos anos 6o. A legalidade e o plebiscito centram-se na defesa das instituições constitucionais. Ainda que parte das forças políticas já defendesse abertamente a ruptura institucional, a defesa da ordem constitucional e a realização de mudanças dentro do sistema encontrou apoio e levou à soluções que mantiveram a democracia.

Após a retomada do presidencialismo, a noção de reformas passa a ocupar a agenda política, seja como proposta, pela situação, seja como denuncia, pela oposição. Assim, a ordem constitucional deixa de ser um elemento central para ambos os lados. $\mathrm{O}$ conceito de democracia passa a estar entrelaçado à possibilidade de mudanças. A democracia popular é contraposta à democracia das elites, em que as regras são o empecilho usado para evitar as reformas.

Esta inflexão também permite que a oposição passe a articular a sua posição em torno da defesa da ordem - não a democrática - mas o respeito às instituições consideradas superiores ao processo político e mais importantes - a família, a propriedade.

Não por acaso os militares articulam a justificativa de sua legitimidade não negando a ruptura da ordem legal, mas pela defesa dos valores superiores, colocados em risco pelo inimigo comunista.

Institucionalizada a nova ordem, muda sua fundamentação, que volta a incluir a defesa da democracia, a "autêntica ordem democrática", sob a responsabilidade do novo regime.

Provavelmente a continuidade da defesa da democracia em seus elementos formais pelo Governo Goulart não tivesse sido suficiente para evitar o movimento golpista. Mas teria obrigado os setores oposicionistas a articular de outra forma a sua posição e a construção do apoio popular ao golpe.

A defesa de mudanças sociais para além dos limites da ordem institucional, articulada por Goulart na defesa das reformas de base teve como contraponto a ruptura da ordem com a justificativa de defesa de valores superiores que seriam o fundamento último das instituições: família e propriedade.

O que pode se verificar, que não apenas os conflitos institucionais, mas a própria posição dos atores envolvidos sobre os cenários legítimos possíveis se alterou ao longo da década, radicalizando posições e reforçando as bases para a possibilidade da ruptura. Vinte anos se passaram depois do golpe até que a defesa da democracia em seus elementos formais, como a eleição direta para presidente, se tornasse um discurso dominante na população brasileira, ainda que vencido pelas restrições 
Campos Neutrais - Revista Latino-Americana de Relações Internacionais Vol. 1 No 1, Janeiro - Abril de 2019

institucionais impostas pelos militares, na votação da Emenda Dante de Oliveira, das "Diretas Já".

O debate político recente trás alguns ecos do passado, com alguns candidatos à Presidência em 2018 reivindicando a necessidade de criar uma nova constituição para avançar no reconhecimento de direitos (uma forma atualizada de "Reformas de Base”) enquanto o candidato vencedor não apenas elogia o passado autoritário, mas ecoa partes da argumentação usada pelos seus instauradores, como a defesa de valores tradicionais de base religiosa com fundamento da ordem pública que justificam o ataque a adversários que não os compartilham.

Este paralelo deve servir de alerta. Da mesma forma que a evolução dos discursos dos atores políticos no início dos anos 60 hoje nos permite identificar o caminho que a democracia brasileira trilhou em sua deterioração e derrocada, esperemos que não estejamos destinados a repetir a história. Talvez seja este o momento para um novo movimento da legalidade, rejuvenecido para a conjuntura de um novo século.

Referências bibliográficas

ALVES, Maria Helena Moreira. Estado e Oposição no Brasil (1964-1984). Bauru, São Paulo: Edusc, 2005.

ALMOND, Gabriel e VERBA, Sidney. The Civic Culture - Political Attitudes and Democracy in Five Nations. Newbury Park, Sage, 1989.

BRASIL. Ato Institucional $\mathrm{n}^{\circ}$ 1, de 8 de abril de 1964. Disponível em http://www.planalto.gov.br/ccivil 03/AIT/ait-01-64.htm Acessado em 15.07.2015.

BRASIL. Ato Institucional $\mathrm{n}^{\circ}$ 2, de 27 de outubro de 1965. Disponível em http://www.planalto.gov.br/ccivil_03/AIT/ait-02-65.htm Acessado em 15.07.2015.

BRASIL. Ato Institucional $\mathrm{n}^{\circ}$, de 13 de dezembro de 1968. Disponível em http://www.planalto.gov.br/ccivil 03/AIT/ait-05-68.htm Acessado em 15.07.2015.

BRIZOLA, Leonel. Discurso em Defesa da Legalidade em 28 de agosto de 1961 Disponível em http://legalidade50anos.blogspot.com.br/search/label/Discurso\%20de\%2oBrizola\% 20em\%20defesa\%20da\%20Legalidade Acessado em 15.07.2015.

COMBLIN, José. A ideologia da segurança nacional: o poder militar na América Latina. Rio de Janeiro : Civilização Brasileira, 1980.

CRUZ, Consuelo. Polítical Culture and Institutional Development in Costa Rica and Nicarágua. World Making in the Tropics. New York, Cambridge Univesity Press, 2005.

DENYS, Odílio, HECK, Silvio e MOSS, Gabriel. Manifesto das Forças Armadas em 30 de agosto de 1961. Disponível em

http://legalidade50anos.blogspot.com.br/search/label/Manifesto\%20dos\%2ominist 
Campos Neutrais - Revista Latino-Americana de Relações Internacionais Vol. 1 No 1, Janeiro - Abril de 2019

ros\%2omilitares\%20em\%2orela\%C3\%A7\%C3\%A30\%20\%C3\%A0\%20Jo\%C3\%A30\% 20Goulart Acessado em 15.07.2015.

EASTON, David. An approach to the analysis of political systems. World politics, v. 9, n. 03, p. 383-400, 1957.

GOULART, João. Discurso de Posse em 7 de setembro de 1961. Biblioteca da Presidência da República. Disponível em

http://www.biblioteca.presidencia.gov.br/ex-presidentes/joao-goulart/discurso-deposse/discurso-de-posse/view Acessado em 15.07.2015.

GOULART, João. Discurso na Central do Brasil em 13 de março de 1964. Disponível em http://www.ebc.com.br/cidadania/2014/03/discurso-de-jango-na-central-dobrasil-em-1964 Acessado em 15.07.2015.

LAFER, Celso. JK e o programa de metas, 1956-1961: processo de planejamento e sistema político no Brasil. FGV Editora, 2002.

NEVES, Tancredo. Perfis Parlamentares / organização e ensaio introdutório de Lucilia de Almeida Neves Delgado. - 2.ed. - Brasília : Câmara dos Deputados, Edições Câmara, 2010.

SANTOS, Wanderley Guilherme dos. 64: anatomia da crise. São Paulo: Vértice, 1986.

QUADROS, Jânio. Carta Renúncia, 25 de agosto de 1961. Disponível em

https://pt.wikipedia.org/wiki/Carta Renuncia de Janio Quadros Acessado em 15.07.2015.

VIZENTINI, Paulo Gilberto Fagundes. Relações internacionais e desenvolvimento: o nacionalismo e a política externa independente, 19511964. Vozes, 1995. 